\title{
CONFLICTOS GEOPOLÍTICOS Y TENSIONES EN EL MUNDO ACTUAL
}

\author{
Juan Ignacio Plaza Gutiérrez \\ Departamento de Geografía \\ Universidad de Salamanca
}

\section{Luces y sombras de la Geografía para con la Geopolítica}

No ha sido ni lo está siendo, precisamente, la Geopolítica un área muy cultivada desde la Geografía en España, pese a la evolución e importancia que adquieren los acontecimientos y factores que están desarrollándose en la escena mundial. Las investigaciones, las aportaciones, las contribuciones a un debate abierto y sugerente que podían hacerse desde la Geografía en esta dirección no son, la verdad, muy abundantes. No existe una determinada tradición cultivada sobre estos temas, no abunda la preferencia científica por parte de la comunidad geográfica hacia estos derroteros, no se cultiva este campo de estudio e investigación lo suficiente. No está presente la Geografía, ni lo estamos los geógrafos (¿es ésta una dejación de funciones?), cuando ante las crisis, conflictos, enfrentamientos, etc. que sacuden diferentes rincones de nuestro planeta o que utilizan determinados recursos, factores o elementos para generar división y choque (precisamente Ricardo Méndez, cuyo artículo abre este número monográfico que ahora prologamos, en su reciente publicación El nuevo mapa geopolítico del mundo incide en los términos de «hidropolítica» y «petropolítica» que a este respecto acuñan Ohlsson y Klare, respectivamente, y subraya la expresión «ambientalización de la geopolítica» que Nogué y Vicente recogen en su libro Geopolítica, identidad y globalización), las líneas, columnas y páginas de diversos medios de comunicación escrita o de revistas especializadas están trazadas y glosadas por analistas de otros campos más centrados y orientados en la materia. Puede decirse, sin temor a equivocación, que en este sentido no hay un reconocimiento social en España de que los geógrafos y la Geografía sean competentes en esta materia, no hay una conciencia entre la sociedad de a pie de que esto sea así.

Pese a todo, en la producción y en la literatura científica al uso, si bien no exclusivamente por parte de la Geografía y no sólo en español, no han faltado referencias y trabajos de indudable proyección y marcada referencia. También en la producción que, sin dejar de basarse en rigurosas observaciones y análisis, sin mermar un ápice su valía, es sin embargo más divulgativa y no se encierra en campos científicos precisos. En este sentido, un rápido y sintético recorrido, en el que a buen seguro faltarían más títulos de los que aquí se señalen, nos puede ayudar a entender tales asertos. A mediados del pasado siglo, en 1950, 
Vicens Vives publicó su Tratado general de Geopolítica. El factor geográfico y el proceso histórico, trabajo pionero y ya clásico, donde junto a la proliferación de ejemplos prácticos basados en estudios de caso tomados de distintos países del globo, la aportación de términos y conceptos de referencia y el tratamiento de cuestiones decisivas («glacis defensivo», «exclaves», los problemas de acceso al mar en distintos países, las fronteras, etc.) destaca, de igual modo, una rica y detallada expresión gráfica y cartográfica propia de los medios de entonces pero abundante en significado y capacidad de transmisión. Desde entonces se han ido sucediendo muy diversas contribuciones que para nada pueden justificar la ausencia de estudios y análisis en este campo; todo lo contrario, han proporcionado muchas fuentes y recursos.

Vienen inmediatamente a la memoria aportaciones y autores de reconocida trayectoria y proyección, de entre las que descuella la del profesor Yves Lacoste, cuyas principales contribuciones en esta dirección se concentran a partir del último cuarto del siglo XX, momento en el que, tras publicar en 1976 el trabajo La géographie, ça sert, d'abord, à faire la guerre 1 , y que ya marcase entonces planteamientos «provocadores» o generadores de polémica, inició además su andadura la revista trimestral dirigida por él, Hérodote. Stratégies, géographies, idéologies. La revista Hérodote es una publicación periódica que, en palabras del profesor Nicolás Ortega ${ }^{2}$ sitúa sus planteamientos y pretensiones desde el primer momento «...en el terreno del análisis crítico de esas implicaciones políticas y militares y de esas relaciones del saber geográfico (saber estratégico) con el poder, en el terrerno de la explicitación de los mecanismos ideológicos que procuran disimular y enmascarar esas importantes implicaciones y relaciones, en el terreno también de la búsqueda de un geografía alternativa» (pg. 8). Ya con posterioridad, fundó en 1989 el «Centro de Investigación y Análisis de Geopolítica», que luego se convirtió en «Instituto Francés de Geopolítica» (dirigido por una de sus discípulas, Beatrice Giblin); en 1993 publicó el Dictionnaire de Géopolitique (Ed. Flammarion) y, más recientemente, Géopolitique. La longue histoire d'aujourd'hui (Larousse, París, 2006) ${ }^{3}$, obra dividida en cuatro partes que repasan desde la conceptualización o entendimiento de esta disciplina, la Geopolítica, hasta los denominados «puntos calientes del planeta», pasando por una revisión analítica de la geopolítica de las grandes naciones.

Junto a la obra del profesor Lacoste, también la producción geopolítica en lengua francesa tiene a Jean Gottmann (La politique des Etats et leur géographie, Armand Colin, París, 1952), André L. Sanguin (Géographie Politique, Bibliographie internationale, Les Presses de l'Université de Quebec, 1976; Geografía Política, Oikos-Tau, Barcelona, 1981), Claude Raffestin (Pour une Géographie du pouvoir, Librairies Techniques, París, 1980) o Paul Claval (Espace et pouvoir, PUF, París, 1978 y Géopolitique et géostratégie: la pensée politique, l'espace et le territoire au XXe siècle, Natah Université, París, 1994), representantes distinguidos. Asimismo, la traducción de los Atlas que Gérard Chaliand ha ido editando en los últimos años (Atlas stratégique. Géopolitique des rapports de forces dans le monde, 1983; Atlas du nouvel ordre mondial, 2003) han constituido un material de primer orden. Y no puede dejarse de hacer mención, asimismo, a contribuciones de tanta relevancia, aunque conectadas con otras dimensiones de análisis (la mundialización

1 Traducción española editada por Anagrama, Barcelona, en 1990 como La Geografía, un arma para la guerra.

2 Ortega Cantero, N. en la «Introducción» de Geografías, ideologías, estrategias espaciales, Dédalo Ediciones, Madrid, 1977. Es otra de las obras en la que interviene Lacoste y que del mismo modo logró una amplia difusión.

3 Del que existe traducción en español: Geopolítica. La larga historia del presente, Ed. Síntesis, Madrid, 2009 . 
y el capitalismo) como las de Immanuel Wallerstein sobre el sistema-mundo - en cuatro volúmenes publicados entre 1979 y 2011 -, sobre la decadencia o declive del «poder americano» o sobre la geopolítica y la geocultura; o las de los politólogos Zbigniew Brzezinski, que asesorase en su momento al presidente Jimmy Carter, y del que ha de subrayarse la obra El gran tablero mundial: la supremacía estadounidense y sus imperativos geoestratégicos, y Samuel Huntington, cuya publicación más señera $-E l$ choque de civilizaciones y la reconfiguración del orden mundial-, editada en 1996, fue la continuación y profundización de un artículo publicado tres años antes («The Clash of Civilizations?») con el que motivó el inicio de un amplio debate a partir de la constatación o existencia de tensiones y enfrentamientos entre diversas civilizaciones como una de las variables dominantes del mundo contemporáneo y su estructuración. Igualmente, no puede dejarse pasar por alto la contribución de Peter J. Taylor, Catedrático de Geografía Política primero en la Universidad de Newcastle y luego en la de Loughborough (Reino Unido), del que su exponente más significado es el libro Political Geography: WorldEconomy, Nation-State and Locality 4 y en el que pone de relieve un claro renacimiento de la Geopolítica.

También la Geografía española, pese a que lo ha hecho de forma desigual y, como se señaló antes, con una cierta discontinuidad y debilidad y/o ausencia, ha contribuido a su manera al cultivo de esta disciplina. Si el historiador Vicens Vives publicó su obra, antes señalada, en 1950, un año después Manuel de Terán hacía lo propio con Introducción a la Geopolítica y a las grandes potencias mundiales (Ed. Atlas, Madrid, 1951). Más cercana en el tiempo es la aparición, en 1984, del volumen 17 de la colección «Cuadernos de Estudio-Serie: Geografía» publicado por la editorial Cincel y que, escrito por los profesores Méndez y Molinero, llevaba por título Geografía y Estado. Introducción a la Geografía Política. Desde las primeras líneas de la «Introducción», los autores transmitían ya su preocupación porque «la geografía política es, por el momento, una disciplina mal conocida y apenas cultivada dentro de la bibliografía española....», tesis que ya al inicio de esta presentación recogíamos igualmente. De igual modo, esta significativa contribución de la Geografía española, breve manual básico e introductorio para estudiantes de Geografía, encontró cierta continuidad en el trabajo «El resurgir de la Geografía Política» con el que el profesor Ricardo Méndez colaboró en la obra colectiva Teoría y práctica de la Geografía (Alhambra Universidad), coordinada por la profesora García Ballesteros en 1986. Son ambos dos apreciados botones de muestra que contribuyeron a rescatar y difundir la preocupación por la Geopolítica (y/o por la Geografía Política, pues las discusiones teóricas sobre ambos conceptos parecen distinguir entre una y otra según unos, frente a otras opciones que los hacen equivalentes) desde la Geografía. Y varias más han sido las aportaciones que, bien de modo concomitante con las señaladas, bien con posterioridad, han ido engrosando los trabajos sobre los que poder fundamentar una perspectiva analítica, de estudio e investigación en esta dirección. Citemos solamente los ejemplos (aun siendo una muestra incompleta) de Joan Eugeni Sánchez (Poder y Espacio, Geocrítica, no 23, 1979; La Geografía y el espacio social del poder, Los Libros de la Frontera, 1981; Geografía Política, Ed. Síntesis, 1982), de Lorenzo López Trigal y Paz Benito del Pozo (Geografía Política; Cátedra, 1999), de Joan Nogué i Font y Joan Vicente Rufí (Geopolítica, identidad y globalización, Ariel, 2001) o la más reciente y más arriba reseñada de Ricardo Méndez (El nuevo mapa geopolítico del mundo, Tirant lo Blanch, Valencia). El mismo Boletín de la Asociación de Geógrafos Españoles (BAGE), dedicó

4 Una primera edición en español se publicó en el año 1994 con el título Geografía Política: EconomíaMundo, Estado-Nación y Localidad (Trama Editorial); en 2002 se ha procedido a una $2^{\text {a }}$ edición. 
su número 17 (año 1993), coordinado por el profesor Joan Nogué i Font, a los conflictos geopolíticos y las transformaciones territoriales de la Europa contemporánea, queriendo de este modo contribuir desde la ciencia geográfica al debate y análisis sobre los cambios y las evoluciones del mapa y las sociedades de la Europa de finales de siglo, a las puertas de un nuevo milenio y proporcionar así materiales e ideas de fondo para una más amplia línea de estudio e investigación. Se quería, también, «visibilizar» y difundir la reflexión que sobre estos aspectos se venía haciendo desde la Geografía española. Finalmente, algunos trabajos han bordeado el campo de la Geopolítica (y de la Geografía Política) en sus análisis que iban más bien orientados a otras temáticas con las que en parte ésta se relaciona: los procesos electorales, la administración y el gobierno del territorio, estudios de zonas de frontera, etc.

En último término, ha de reconocerse, de igual manea, la indudable función positiva que ha tenido sobre el impulso a estos estudios y análisis la aparición de publicaciones y producciones, como se señaló al principio de estas páginas, que, sin dejar de basarse en rigurosas observaciones, son más divulgativas y no se encierran en campos científicos precisos. Y aquí se han de citar dos ediciones que constituyen un contexto y una referencia de marcada necesidad: la edición española de la publicación Le Monde Diplomatique y los dossiers que, periódicamente, edita La Vanguardia. El primero edita un Atlas Geopolítico (la última edición es la de 2011) que recoge en perfecta síntesis los principales ejes de análisis e interpretación del mundo contemporáneo; junto a él, y de modo complementario, ha editado otros atlas temáticos (por ejemplo, de las minorías) que consolidan más aún las fuentes con las que poder realizar una rigurosa interpretación de la evolución del mundo actual. Este mismo medio de información ya publicó en 1999, en la editorial Temas de Debate, la obra Geopolítica del caos, manual de consulta imprescindible para el entendimiento de cómo se gestan el mundo y las sociedades del siglo XXI. Por su parte los dossiers de La Vanguardia van ya por su ejemplar $\mathrm{n}^{\circ} 42$ y proporcionan una enjundiosa fuente de información y conocimiento sobre cuestiones y áreas de ámbito internacional muy actuales.

\section{Geografía de los conflictos y de las tensiones en el mundo actual}

El panorama del mundo actual nos traslada un mapa donde se hacen evidentes conflictos, enfrentamientos, crisis y tensiones de dispar intensidad y manifestaciones presentes en todos sus continentes. Pero al mismo tiempo, también se han reforzado los medios (recursos financieros, recursos personales - fuerzas especiales, cuerpos de voluntariado, ONG, etc.- , organismos y entidades internacionales de desigual alcance, etc.) y han proliferado misiones especiales e intervenciones precisas, si bien es cierto que no por ello han desaparecido los enfrentamientos y que en algunos casos las sombras que han arrojado determinadas actuaciones internacionales en algunos de estos conflictos han contribuido a cuestionar la credibilidad en la eficacia de las mismas así como de las instituciones que las respaldaban.

Naciones Unidas sustenta en la actualidad 17 misiones e intervenciones de paz, control y seguridad, algunas de las cuales se iniciaron ya hace bastantes décadas ${ }^{5}$, que representan unos recursos financieros para este último periodo (2011-2012) de cerca de 8 billones de $\$$ USA $(7,84)$ más otros 1,8 pendientes de pago. También la OTAN ha desplegado distintas operaciones militares en diferentes regiones: Afganistán (la

$5 \quad$ UNFICYP en Chipre, 1964; FPNUL en Líbano, 1974; ONUVT en Oriente Medio en 1948; FNUOS en los Altos del Golán desde mayo de 1974; UNMOGIP en India y Pakistán desde 1949; MINURSO en el Sáhara Occidental desde 1991 (Fuente: http://www.un.org/es/peacekeeping/). 
reconstrucción del país y garantizar un gobierno eficaz son sus objetivos); Cuerno de África/Golfo de Adén (control de la «piratería» marítima para garantizar la seguridad el tráfico de navíos); Sudán (proporcionar medios aéreos para transportar fuerzas militares suplementarias para el mantenimiento de paz en la región de Darfur); la cuenca del Mediterráneo (en el marco de la denominada «Operación Active Endeavour» ${ }^{6}$, apoyando la detección, disuasión y protección frente a buques sospechosos de realizar actividades relacionadas con el terrorismo); o Kosovo (desde junio de 1999, donde las «Kosovo Force», KFOR, o «Fuerzas para Kosovo», fuerza militar multinacional pero liderada por la OTAN, intervienen apoyando iniciativas desarrolladas a escala internacional para instaurar la paz y la estabilidad en la zona). Asimismo la Organización para la Seguridad y Cooperación en Europa (OSCE) cuenta en su estructura, y dependiendo del Secretario General, del denominado «Centro de Prevención de Conflictos» (CPC). Es éste un órgano cuyas funciones atienden a los ámbitos de la alerta temprana, la prevención de conflictos, la gestión de crisis y la rehabilitación posterior a los conflictos.

África (sobre todo Africa Central y Ecuatorial, también en el Norte - la denominada «primavera árabe» es el mejor testimonio-), Asia (especialmente en el SE asiático y en Afganistán y bordes limítrofes) y Oriente Medio son las principales áreas geográficas sobre las que se despliegan la mayor parte de las misiones de mantenimiento de paz promovidas por las Naciones Unidas que antes se han reseñado, pero también, aunque con menor representación actual (más lo fueron en décadas anteriores), América Latina y Europa. Y en algunas de ellas se ha producido una conjunción e intersección de intervenciones tanto de Naciones Unidas como de la OTAN (Kosovo, Darfur y Afganistán, por ejemplo).

Y hoy, en pleno siglo XXI, iniciada ya su segunda década, hemos de hablar del mantenimiento de tensiones, litigios y conflictos en pleno suelo europeo, sin desplazarnos a otras áreas geográficas. Aún siguen abiertas razones de confrontación y roces de desigual intensidad y con muy contrastadas posibilidades de resolución. Evidentemente ni todos responden a las mismas razones ni han desembocado en enfrentamientos armados (puede afirmarse que solo hay riesgo, y ha habido conflicto armado intermitente en el último año, en uno de ellos: los enfrentamientos en el Cáucaso en regiones separatistas de Georgia y apoyadas por Rusia). Un simple repaso a una sucinta relación de todos ellos nos dibuja un significativo mapa de Europa que debe de considerarse en su definición política del siglo XXI. Algunos alientan el surgimiento y consolidación de nuevos escenarios de tensiones y enfrentamientos en torno a los océanos y mares - y de nuevas orientaciones de la Geopolítica en su análisis, como la llamada por algunos autores «Oceanopolítica»—, tal y como sucede en el Oceáno Ártico en torno a la disputa de los recursos que alberga su fondo y que protagonizan los países ribereños ${ }^{7}$ (Rusia, Suecia, Noruega, Islandia, Dinamarca - Groenlandia-, junto con Estados Unidos y Canadá). Pero en el caso del Ártico no son solo los recursos la causa de tensión y disputa, también las demarcaciones territoriales y el control de pasos y rutas. Igualmente geoestratégicos son los planteamientos y movimientos que enmarcan el conflicto de las rutas de los gasoductos y oleoductos que tienen su origen en Rusia y se dirigen hacia territorios de Europa Central y Oriental o desde las riberas caucásicas del Caspio: como en el caso del Ártico, pero indudablemente

6 Que surgió como una de las medidas que la OTAN acordó como respuesta inmediata a los ataques del 11 de septiembre de 2001.

$7 \quad$ El 24 de febrero de 2008 el diario El País publicaba un amplio artículo significativamente titulado «La frontera blanca del oro negro» (páginas II y III del suplemento «Negocios») donde se resumía que «En el Ártico se juega una batalla geopolítica. El aumento de la demanda energética y el deshielo del casquete polar por el calentamiento global han impulsado las reclamaciones sobre la zona de sus vecinos por la gran cantidad de recursos minerales que contiene». También por los hidrocarburos. 
con otros tintes, de nuevo los recursos protagonizan las tensiones y confrontaciones entre países y regiones de Europa.

Por otra parte, conflictos más conocidos, donde la violencia ha estado presente hasta hace poco y aún constituye una amenaza, son los desarrollados en territorios del Cáucaso, máxime cuando a mediados del año 2008 la Federación Rusa reconoció la independencia de las regiones separatistas de Abjazia y Osetia del Sur. Como tensos son (o fueron) también los casos de las disputas territoriales de Bosnia-Herzegovina entre las dos grandes regiones que articulan el territorio, de la autoproclamada independencia de Kosovo y su relación con la minoría serbia, o de los enfrentamientos que sucedieron en los primeros momentos a la autoproclamada República de Trandsnistria (Moldavia), todavía no reconocida por nadie.

De diferente calado y aparentemente más «tranquilos» (lo que no significa exentos de sobresaltos) son los roces que se producen entre flamencos y valones en Bélgica, amenazando seriamente la estructura política de un país situado en el corazón de Europa y cofundador de la actual Unión Europea; de Grecia y Turquía en torno a ciertas delimitaciones y posesiones marítimas en el Egeo; del enclave ruso de Kaliningrado y su nueva definición dentro de una Unión Europea ampliada; o de reivindicaciones con ribetes históricos por su prolongación en el tiempo pero poco generadoras de tensiones abiertas, como la cuestión del Alto Adigio-Tirol del Sur (Italia-Austria) o la de la región fronteriza germano-danesa.

Hay, en fin, otros problemas geopolíticos de muy distinto alcance y entidad pero que todos ellos convergen en un punto: siguen sin solución;es el caso de la división de Chipre, el problema de Gibraltar, la situación y consideración de las ciudades de Ceuta y Melilla, la reivindicación siria de su antigua provincia de Alexandretta (hoy Hatay, en el sur de Turquía), el problema kurdo, la resolución del litigio entre Rusia y Japón por el archipiélago de las Kuriles, o del enclave del Alto Karabagh situado en territorio de Azerbaïdján pero mayoritariamente armenio. También los acontecimientos recientes (últimos años) en algunos países de Europa Central y Oriental o las tendencias sociales, políticas y culturales más actuales que han derivado hacia peligrosos derroteros han caracterizado a países como Ucrania (¿una frustrada «revolución naranja»?) o Hungría, Eslovaquia y República Checa (en estos tres últimos casos, no deja de llamar la atención ciertas radicalizaciones de gobernantes y formaciones políticas sospechosas de autoritarismo, así como la excesiva rigidez del control de sus fronteras al tiempo que han llamado a la rebeldía frente a ciertas políticas comunitarias o han perseguido la libertad de expresión de medios de comunicación y grupos sociales). Y junto a este elenco, parece que nos hemos acostumbrado a ver ya territorios amputados, como es el caso de Irlanda (una isla y dos Estados), aunque no por ello deja de ofrecer una contradicción entre lo político y lo geográfico, como sin duda la ofrece el caso chipriota.

\section{Los contenidos de este volumen}

Atendiendo precisamente a tan amplia y contrastada variedad de situaciones a escala mundial, este número de la revista Investigaciones Geográficas, que acertadamente han impulsado desde su Consejo de Redacción, pretende ofrecer un conjunto de materiales, reflexiones y análisis que, coordinados desde la Geografía pero, como no podía ser menos tampoco, abiertos a otras áreas, profesionales y estudiosos de los temas geopolíticos, proporcione recursos y argumentos de gran utilidad para conocer e interpretar el mundo actual y abra una traza por la que discurra y se vaya conformando un debate continuo y enriquecedor y una tendencia de estudios e investigaciones que profundicen sobre la evolución del mundo actual y enriquezcan los contenidos y medios que a tal fin se necesitan. 
Abre este volumen el trabajo del profesor Ricardo Méndez, cuya experiencia le avala sobradamente y que ha sido, tal y como en su momento ya señalamos, uno de los geógrafos que más decididamente han apostado por cultivar y consolidar este área de estudio dentro de la Geografía. En su artículo «Tensiones y conflictos armados en el sistema mundial: una perspectiva geopolítica» se incide en la transformación de las morfologías, áreas de localización, causas y tipos de impactos generados por los conflictos armados generada por el nuevo orden geopolítico mundial posterior al final de la que se dio en llamar «Guerra Fría», coincidente con el actual proceso de globalización. El artículo resume las principales aportaciones recientes sobre estas cuestiones y revisa de forma crítica algunas ideas difundidas en estas dos últimas décadas. También propone un enfoque multicausal y multiescalar de los conflictos armados, destacando las aportaciones que pueden hacerse desde una perspectiva geopolítica.

El profesor Javier Gil Pérez, del Instituto Universitario «Gutiérrez Mellado» (UNED), presenta en su artículo («Mapa de los conflictos de Asia») una actual representación cartográfica de los enfrentamientos y tensiones en este vasto continente, dividido a tales efectos en tres zonas: Subcontinente Indio, Sureste Asiático y Lejano Oriente, dejando a un lado Australasia - debido a la ausencia de conflictos que afectan a la zona - y Asia Central, que se incluye dentro del conflicto afgano. Pakistán y China son los dos principales escenarios que analiza, por tener China en el terreno económico y Pakistán en el ámbito de la seguridad los mayores desafíos. Una región que ha pasado de ser un área pobre y subdesarrollada con poca influencia internacional, a ser uno de los tres motores mundiales de crecimiento junto a Estados Unidos y Europa. El trabajo pone de manifiesto cuáles son las principales fuentes de inestabilidad que pueden truncar este magnífico crecimiento político y económico de Asia.

Las frecuentes colaboraciones escritas del profesor Ignacio Alvarez-Ossorio en diferentes medios de comunicación nacionales proporcionando luces y razones a la interpretación de cuanto sucede en los países árabes, son una sobrada razón para contar en este caso con su experiencia y conocimientos, máxime con la trascendencia de la denominada «primavera árabe» que se ha extendido desde 2011. En su artículo sobre «El mito de la conflictivdad del mundo árabe. De la época colonial a las revueltas populares», procede al análisis crítico de la argumentación que de forma tan frecuente y recurrente se ha esgrimido al describir al mundo árabe como conflictivo, dada la prolongación en el tiempo de conflictos, hostilidades y tensiones entre algunos de sus países. Se contraargumenta frente al manido «factor religioso» y al lugar común discutible que aserta que los países árabes serían refractarios a la democracia y proclives al autoritarismo, al tiempo que aboga por contextos más globales que apuntan a razones explicativas de orden político, económico y/o social.

Mbuyi Kabunda analiza en su artículo los conflictos en África, fijándose de modo más particular en el caso de la región de los Grandes Lagos y de Sudán. En su opinión, los conflictos africanos tienen cada uno su especificidad e idiosincrasia, pero se encuentra en todos un denominador común en las luchas manipuladas entre las nacionalidades, por una parte, y los nacionalismos estatales, por otra, y últimamente por el afán por el acceso a los recursos naturales. En el caso particular de los Grandes Lagos, es preciso subrayar que los conflictos nacen de la instauración de un «etnicismo científico», junto a la desaparición del aparato del Estado en la República Democrática del Congo, dando lugar a un saqueo de recursos naturales en este país. Por su parte, en Sudán los conflictos surgen fundamentalmente de las desigualdades de toda índole entre el centro y las periferias de este país (el Sur de Sudán y el Darfur). Apuesta el profesor Kabunda, finalmente, porque la solución en ambos casos pase por la creación de Estados de derecho (el fin de la cultura de la impunidad) y la descentralización (federalismo). 
Silvia Marcu tiene entre sus múltiples líneas de investigación el análisis geopolítico de las márgenes orientales del continente europeo y del territorio ruso y postsoviético. Es dilatada su producción científica a este respecto. En el trabajo que aquí se recoge incide en que una de las herencias de los últimos años del comunismo en la Unión Soviética (URSS), para la nueva Rusia, consistió en los conflictos de naturaleza étnica o confesional que estallaron cuando la opresión política del régimen dejó de paralizar el espíritu nacional. El artículo presenta el laberinto de las tensiones y de los conflictos generados por la mezcla de naciones, etnias, y por la intensa fragmentación vivida en el espacio postsoviético después de la caída de la URSS. Se procede a estudiar los factores condicionantes que desencadenaron dichos conflictos y tensiones, así como a realizar una breve síntesis de los focos más importantes donde los mismos se produjeron.

El artículo de José Luis Cadena Montenegro parte de la idea de que la importancia geopolítica de Sudamérica frente a los planes de los Estados Unidos, para mantener la hegemonía global, está intrínsecamente vinculada a su dimensión económica y comercial. Recursos estratégicos como el agua y el petróleo escasean a nivel mundial y las principales reservas se ubican en Sudamérica; por esa razón es importante para los Estados Unidos declarar estos sitios como propiedad de la humanidad, para administrarlos en el futuro con el pretexto de la «destrucción del medio ambiente por parte de sus pobladores». Los problemas que contribuyen a la destrucción del entorno son, ante todo, acciones de índole antrópica y cultural, cuyas raíces se encuentran en el orden económico y social que determina las formas de vida de una sociedad estimulando el consumo mediante la aculturación. Paradójicamente, el subcontinente con mayor biodiversidad, afronta problemas de pobreza, hambre y violencia que lo mantienen en el grupo del Tercer Mundo.

Francisco J. Torres Alfosea colabora con su trabajo «Fracturas y tensiones entre Oriente Próximo y el sureste europeo: el Kurdistán», conflicto, éste último, que al decir del autor no sólo es uno de los de mayor duración y gravedad en todo Oriente Medio, sino que ante todo debe considerarse un conflicto regional, que interesa no sólo a Turquía, sino a todo Oriente Medio y, de forma indirecta, a las relaciones económicas, militares y diplomáticas entre Occidente y el mundo islámico. Sostiene el profesor Torres que los kurdos han visto cómo sus aspiraciones de obtener un Estado libre e independiente, que alguna vez le fueron reconocidas, están hoy más lejanas que nunca. Y llama, asimismo, la atención sobre el hecho de que el debate de este conflicto geoestratégico suele olvidar las relaciones de poder internacional que en él convergen, y tiende a reducirse a una lucha entre dos grupos, a focalizarse en el detalle de las acciones violentas, y asignando roles a las partes en conflicto. La lucha por los derechos humanos y el derecho de libre determinación deberían estar, también, en el discurso sobre este conflicto.

El trabajo que pone el punto y seguido (que no final, por cuanto se pretende encauzar el debate y continuar líneas de investigación) a este volumen lo firma el profesor Manuel Mollá Ruiz-Gómez, buen conocedor del terreno del que habla. «La región fronteriza México-Estados Unidos, un lugar de unión y desencuentros» es su título y en él se parte del planteamiento de que este límite fronterizo es mucho más que una línea de división y de conflictos. Es una región integrada, a pesar de las dificultades, bien delimitada geográficamente y con una serie de intereses e instituciones comunes que hacen que, desde la Geografía, tenga un notable interés. La línea divisoria que une y separa a, según muchos autores, el primer del tercer mundo, pero que comparten dos países que firmaron un tratado de libre comercio y que para México supone un acuerdo con el país que es su mayor socio comercial. Ver cómo funciona esa frontera y su correspondiente región es el principal objetivo de su artículo. 
Estamos, en suma, ante una sustanciosa, elaborada y enriquecedora aportación científica que realza el valor de la Geopolítica (¿y la Geografía Política?) como ámbito interdisciplinar de estudio e investigación y al que desde la Geografía española como ciencia y como colectivo, en estrecha interrelación con otras áreas y campos afines,y desde uno de sus medios de difusión científicos, la revista Investigaciones Geográficas, se le quiere otorgar el valor que merece y considerar como herramienta imprescindible en la valoración y entendimiento del complejo y abigarrado mosaico de territorios, sociedades, naciones, estados y pueblos que entretejen el mundo actual, que ha iniciado su andadura hace pocos años por un nuevo milenio de horizontes difusos y cargados de incertidumbres (la profunda situación de crisis) que pueden entorpecer su evolución. 